- LA-UR- $31-1502$

$$
(0,1)
$$

Los Alamos National Laboratory is operated by the Univerwiy of Californis lor the United Stater Department of Energy under contract W.7405.E NG. 36

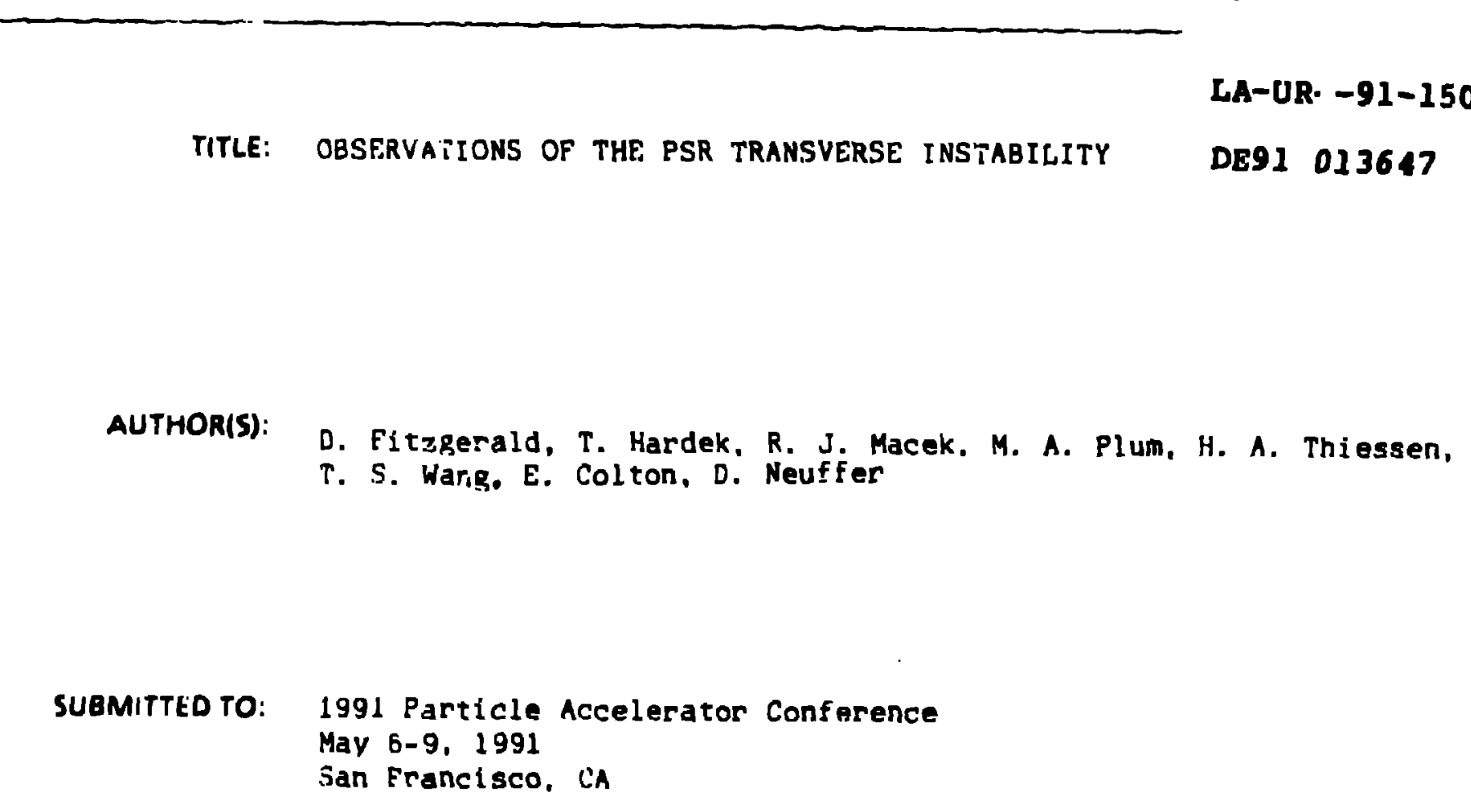

\title{
DISC I.AIMER
}

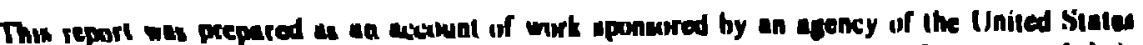
(iovernment. Nelther the (Inited situles (kmernment nor any agency thereof, mor any of their

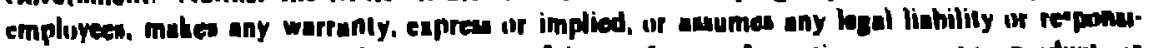

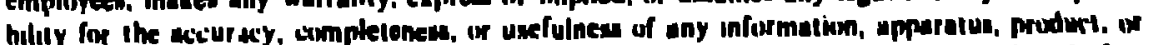

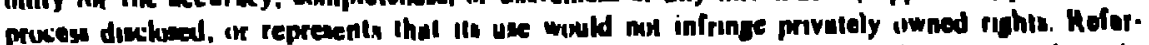

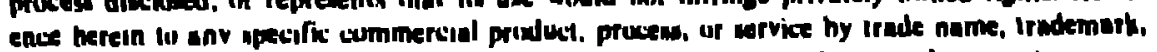

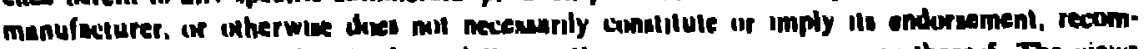

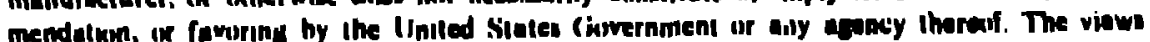

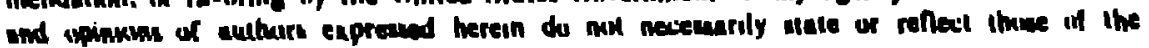
Iniled siates (kwernment of any agency therent
\end{abstract}

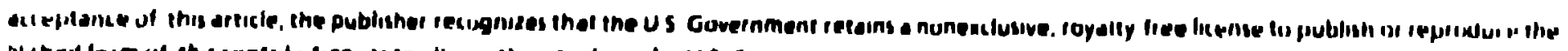
ilished to m of this contribution or to alluw uthers tu do so, lor US Government putpoies

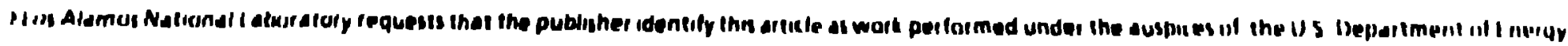

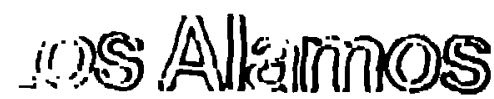

is Alamos Nulioneal Liboralory is Alenios Now Moxico 87545

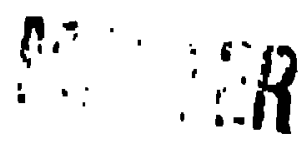




\title{
Observations of the PSR Transvers? Instability*
}

\author{
E. Colton \\ EK-92, GTW, US Department of Euergy, Washington, DC 20545 \\ D. Fitzgerald, T. Hardek, R. Macek, M. Plum, H. Thiessen and T. Wang \\ Los Álamos National Laboratory, Los Alamos, NM 87545 \\ D. Neuffer \\ CEBAF, Newport New, VA 23606
}

\begin{abstract}
Abotract
A fast instability with beam lose is observed in the Los Alamos Pruton Storage Ring (PSR) when the injected beam current exceeds thresholds, with both bunched and unbunched beams. Large coherent tranoverse oecillations occur before and during beam loss. Recent observations of the instability indicate that it is an "e-p"-type instability, driven by coupled oscillations due to electrons trapped within the proton beam.
\end{abstract}

\section{INTRODUCTION}

The PSR is a fast-cycling, high-current storage ring designed to accumulate beam over a macropulse of the LAMPF linac ( $\sim \mathrm{ma}$ ) by multiturn injection through a stripper foil, and compreas that beam into a short, singlecurn extracied pulse $(\sim 0.25 \mu s)$. Key PSR parameters include beam kinetic energy $T=797$ Mlev; circumference $2 \pi R=90.1 \mathrm{~m}$; revolution frequency $\Omega / 2 \pi=2.795$ MHz; betation cunes $Q_{s}, Q_{y} \approx 3.17,2.13$; and current operating intensity $N \approx 2.35 \times 10^{13}$ particles. 'The design intensity is $100 \mu \mathrm{A}$ on larget at $12 \mathrm{~Hz}$, which implies $5.2 \cdot 10^{11}$ protons/pulve. Average and peak intensities have been somewhat less ( $80 \mu \mathrm{A}$ at $20 \mathrm{llz}$ in 1090, and 1.101.7 maximum pulse size). The average currelit has bren limited by slow beam loses, and individinl pulse intensities are linited by the fast instability.

The instability appears when more than $\sim 15 \times 10^{1.7}$ protons are stored in bunched mode (If on) and whe'l more than $0.5 \cdot 10^{1.7}$ are stored in unbunched modr. Transverse oscillations at $\sim 100 \mathrm{MHz}$ are srell, and grow exponentially at time ucales of 10-100 $\mu \mathrm{m}$, causing benu lasure (see tig. 1). Initial experimente and observations of the instability reported by Neufter et al. (1) showred dependences of the thresholdn on if voltage, hram size, momeutum apreal, and sextupole and octupole strengtha. Impedance couplingo were musperted to be the inuser of thr inmeahility. Senrehes for a pomilile im.redan:er murer wrepe unnuermuful, and recent oheervations (both with IInbunclied and with bunched benmi) are not ronsintent with a liariware impedance sourer. The obarervationa are connintent with thre poasibility that thre instability in all op instability, and supporting eadrulations have show In than ronditionn for r-po inntability may orcur with buncherl henum in the ISR $[2,3]$.

In an $n p$ inntability, barkgrnund low-ent rgy elerctrons

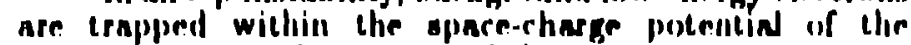
rirculating protom beam. ('oupled tranis verwe coreilintions of

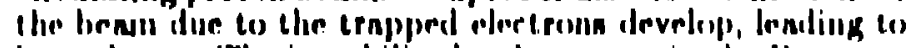

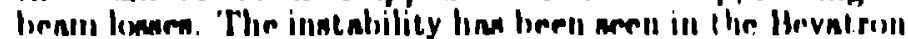

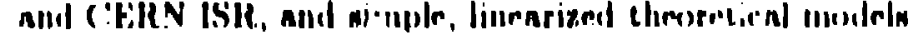

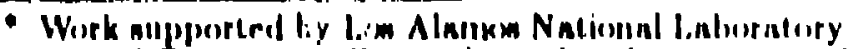

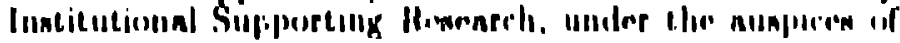

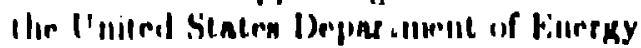

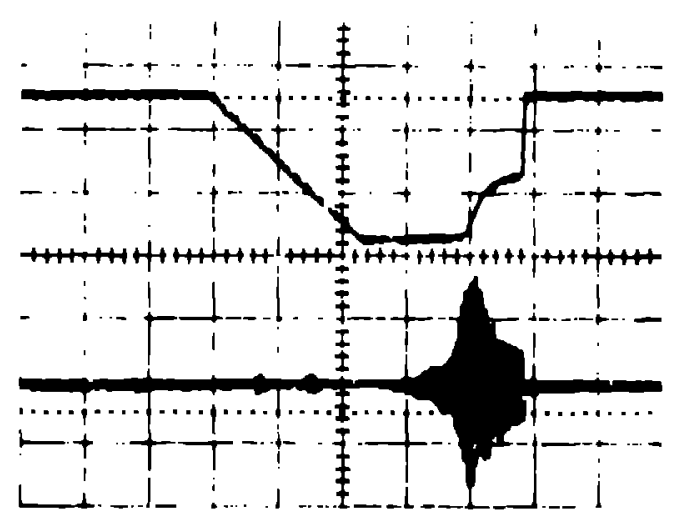

Fig. 1. Bean current (upper trace) and vertical difference signals (lower trace) under unstable conditions.

have been developed [4.5]. The equationa for the coupled vertical motions of the protons and electrons within the beams are:

$$
\ddot{y}_{p}+\left(Q_{y}^{2}+Q_{p}^{2}\right) \Omega^{2} y_{p}=Q_{p}^{2} \Omega^{2} \bar{y}_{\bullet} \quad,
$$

and

$$
\ddot{y}_{0}+Q_{e}^{2} \Omega^{2} y_{e}=Q_{e}^{2} \Omega^{2} \bar{y}_{p} .
$$

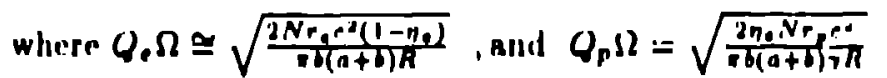

'The motions are coupled through the center of Illawn $y_{e}$, $v_{p}$ oscillations. Amuming harmonir motion obtining thre ifispersion relation.

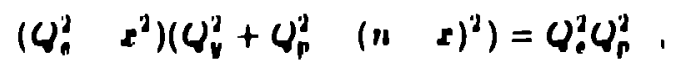

where $\mathcal{f}=w / S)$ in the iwrillntion frequency : Irrmis of

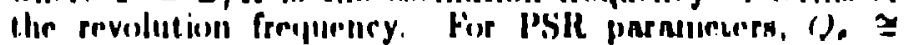
10) ( 100 MI/z). 'Ilue diwpersion relation has colliplex molutiona (iuntulility) mens $s \approx Q_{a} \approx n \quad Q_{y}$, provileod

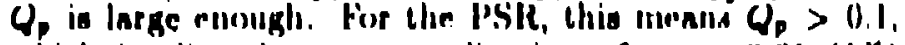
whirh inuplim that a nerutralization of $\eta_{0}>0.01(1 \%)$ ran Irad to innenbility at. n relabivaly low electron drnaity. Some nealilization by lamilau danping (frepluency npereme) in vomilole; the atabilization efferts nern in the PSIt wre

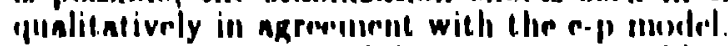

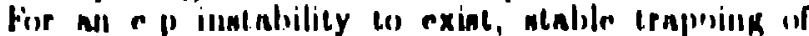

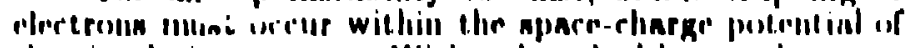

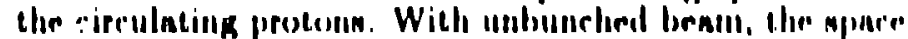

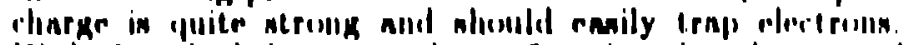

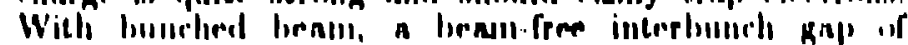

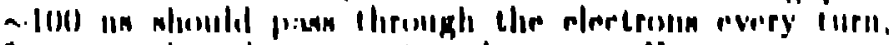

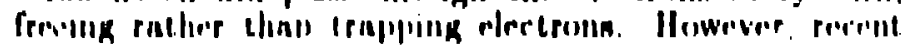


calculations [2] have shown that if a low-density bearn having amoott overall density diatribution, leaks into the gap, electron trapping can oceur with bunched beam at PSR parameters. Recent experiments (sec Section II) do show that the instability is associatad with beam leakage, and that such leakage is a plausibit result of the PSR longitudinal dynamics, involving of vol age (relatively small eflect), longitudinal apace charge (large effect), and injection phase-ope:e mismatch (large effect).

\section{RECENT PSR EXPERIMENTS}

The results of these experiments are reported in detail in a forthcoming article [3]; we sumunarize some critical observations below.

\section{A. Background Charge Experimento}

An e-p inatability depends on a cource of electrons that can be trapped within the circulating proton beam. Possible sources include secondaries from besmfoil interactions, beam-gas interactions, and beam losees on the wals. Both beam-foil interactions and beam losses are relatively large in the PSR. Also, there are no elearing clectrodes to remc'e charges. In some recent experiments, PSR bnckground charge conditions have been modified, leading to changes in instability thresholds. Such changes are not consistent with $Z_{\perp}$-inatability, which should be independent of background.

In one experiment, sufficient voliage was placed on the foil to clear electrons in the vicinity. With unbunched heam, an increase to $300 \mathrm{~V}$ (the expected space-charge potential) increased thresholds by $\sim 10 \%$; but further increases (to $2000 \mathrm{~V}$ ) showed no further improventent. In several experiments, the vacuunn was degraded from $-2-5$ $10^{-A}$ up to $10^{-\mathrm{A}}$ Torr. The beam, bunched or unbunched. becarne more unstable; thresholds were changed by $\sim 10 \%$ 'The further instability could be caused by iucrensed

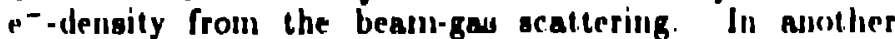
experionent, beam loseen were increaned by moving thr hulo serapeis loward the benm. The beall agnin beraluw mors unatable, even though intensity was decreased. 'The' Inodel is that lowaes increased secendary - $^{-}$produclum, leading to) incrensed inatability. 'That rhangen in $e^{-}$dennity doess rhnnge the atability of the proton hean in consistrut with the e-p inatability hypothesin: however, a dominant osoure has not yet bern identified

\section{b. Gap Filling and Inatability}

('adrulat oun show that bumrlied liram e-p) immtahility

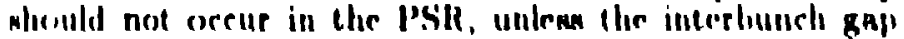
han filled in. Iterent experiminents do inclerd show tilint

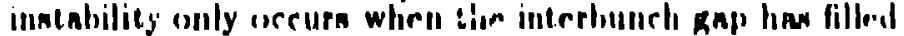

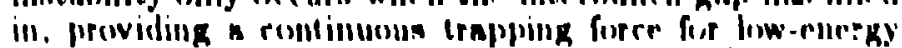

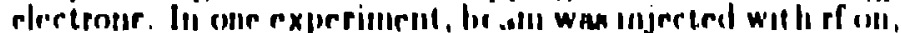

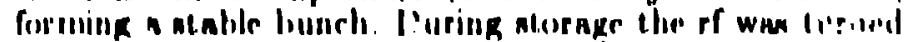

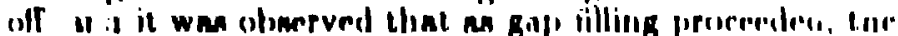
lienm bernure unatentile

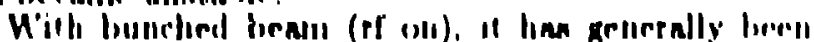
whareved that inatalility corcurm only when the interlumech

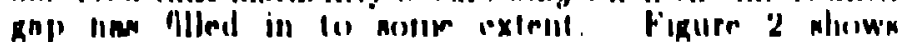

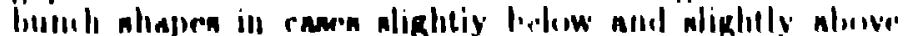

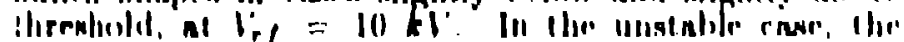

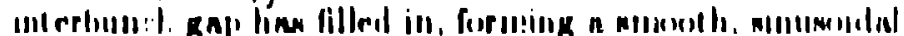

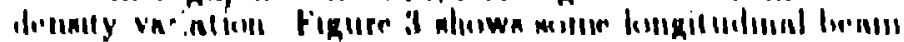

profiles at end of injection. All cases with beam leakage showed atrong instability, and all cases with a beam-free interbunch gap were stable.
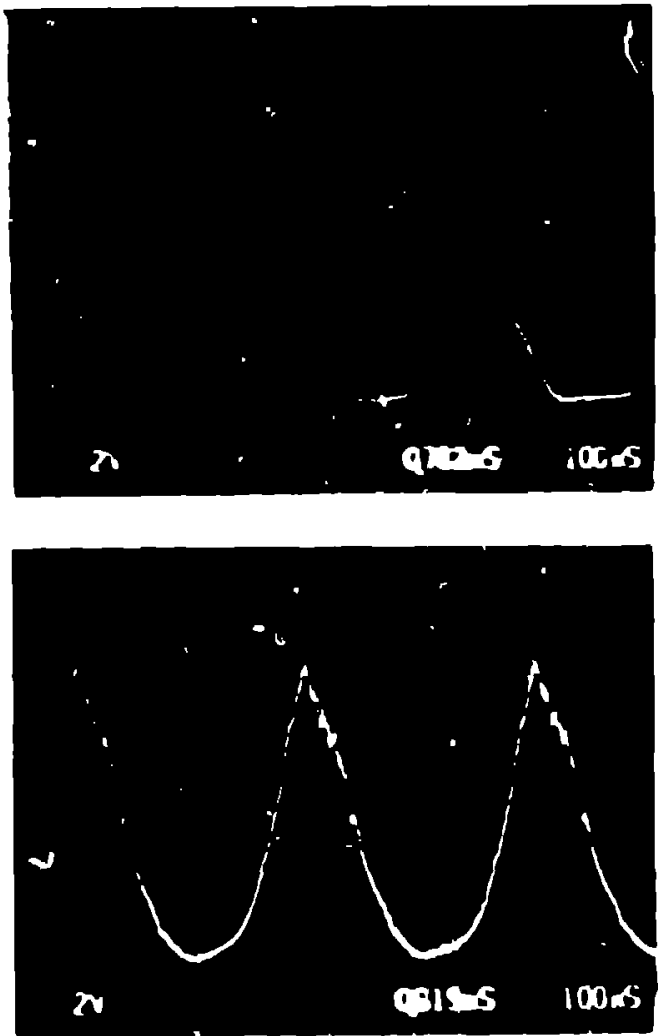

Fig. 2. Beam profiles below and above instability threahold. Note smoothly-filled gap in unstable case.

Menumrembente under various conditions indicale that gap filling orcurs before or simuleaneously with the beginning of exponentially growing oscillations, well be fore

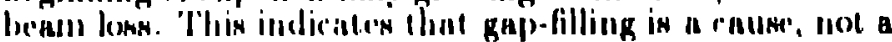
result, of the insulabilits.

In addition, exprerimune were performerd in which a

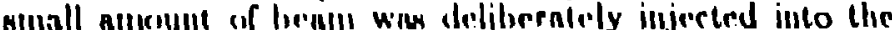
interluneh gup (hy dexeruling injertion rhopping). 'Ther

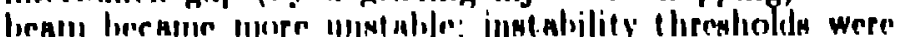
reduced by $221 \%$ \%. In a complementary experiment, beam was kickedl oul of the interhunch gap during utornge (by a

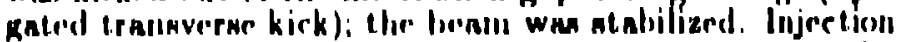

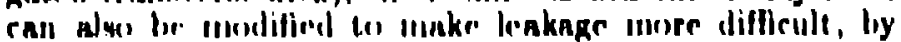
injertiug with n shorter width. Ther bermon in then injerted

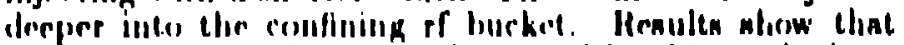

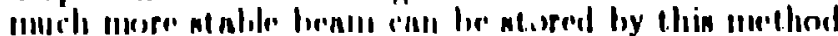

\section{Prequency simetra (Dbaernationa}

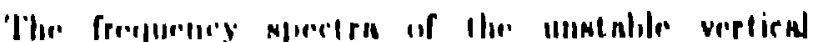

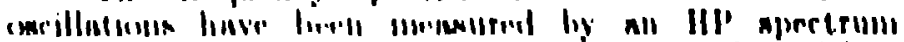

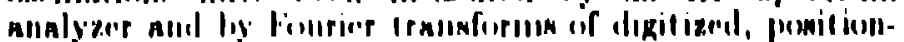

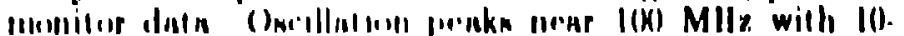

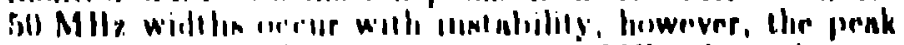

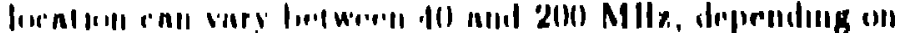

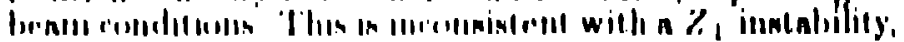

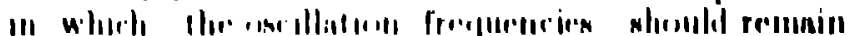



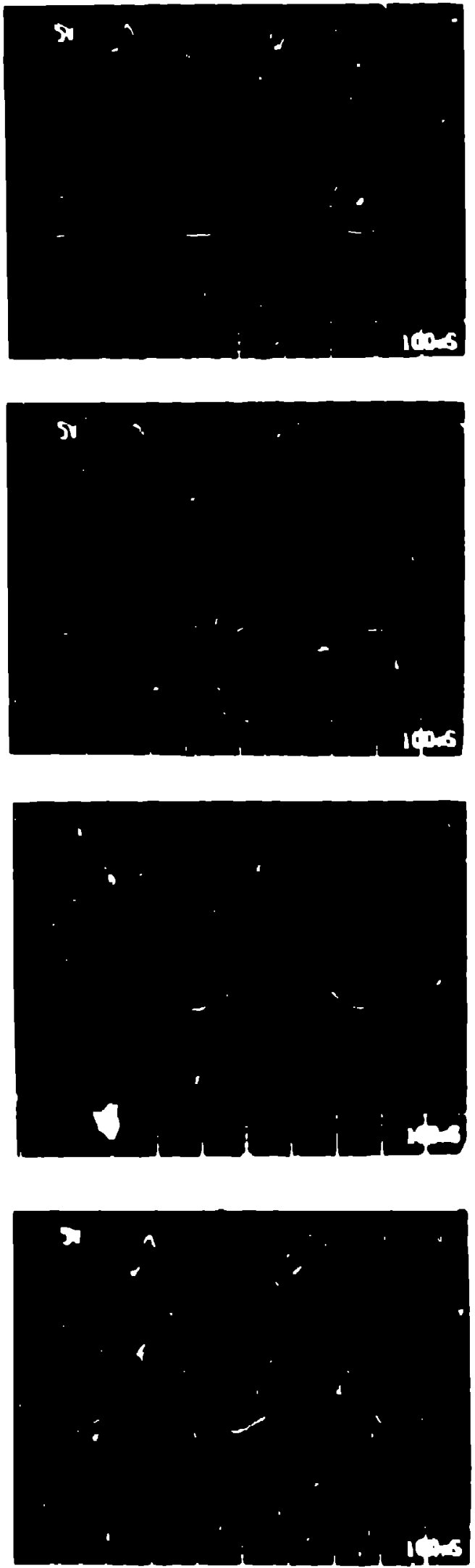

Fig. 3. Heam profllen at end of injertion under ntabler (upper two) and inder unatable (lower two) ionditions. unchanged. However, in an e-p inatability, the frequencies should be near $Q . f_{n}$, and should vary with beam density $\left\{Q_{e} f_{n} \times \sqrt{\left(N^{\prime} / b(a+b)\right)}\right\}$. The variations in peak location and width that we observed are consistent with the measured and expected variations in three-dimensional beam density.

\section{SUMMARY AND DISCUSSION}

Recent experiments and calculations indicate that the PSR transverse inatability is an e-p intability. Because electron trapping, which trigge:s the instability, oceurs only when there is some leakage of beam into the gap, maintaining a beam-free interbunch gap is desirable in PSR operations. Leakage can be ovoided or delayed by inanipulating PSR parameters, ouch 1 injection width, if voltage, and phase; such measures have empirically improved operation ind assisted in increasing intensity to current levels.

Future experiments will search for more definite proof of e-p instability. A critical experiment would be to investigate more fully the use of a tranovere kicker to remove bean from the interbunch gap, to determine whether gap clearing consistently stabilizes the beam. Other experiments should try to identify a dominant $e^{-}$ source (possibly stripper foil or beam losses); this could point the way for installation of clearing electrodes.

\section{REFERENCES}

[1] D. Neuffer, et al., "Trangverce Collective Inntability in the PSR," Particle Aax/emlorn 23, 133 (1088).

[2] D. Neuffer, "Calculations of the Conditions for Bunched-Beam e-p Instability in the Los Alamos Proton Storage Ring," 1891 Particle Accelerator Conference, San Francisco, CA (May 1891).

(3) D. Neuffer el al." "Observations of a Fal trensverse Inatebility in the PSR," submitted to Particle Amolemtors.

[4] H. Grunder and G. Lambertson, "Trangverne Beam Inatabilities at the Bevatron," Proc. 8th Int. Conf. on High "'nergy Accelerators, CERN (1871), p. 308.

[5] E. Kéil and $B$. Zotler, uandau-Damping of Coupled Electron-Proton Oscillticns," CERN ileport CERN/ISK-TH/71.58 (1071). 